\title{
The Physiology of Postharvest Tea (Camellia sinensis) Leaves, According to Metabolic Phenotypes and Gene Expression Analysis
}

\author{
Shuang Mei ${ }^{1,2,+}$, Zizi Yu ${ }^{3,+}$, Jiahao Chen ${ }^{3}$, Peng Zheng ${ }^{3}$, Binmei Sun ${ }^{3}$, Jiaming Guo ${ }^{1,4, *}$ and Shaoqun Liu ${ }^{3, *}$ \\ 1 College of Engineering, South China Agricultural University, Guangzhou 510642, China; \\ meishuang@gdaas.cn \\ 2 Guangdong Academy of Agricultural Sciences, Guangzhou 510640, China \\ 3 College of Horticulture, South China Agricultural University, Guangzhou 510642, China; \\ yzz_123@stu.scau.edu.cn (Z.Y.); cjhtea@stu.scau.edu.cn (J.C.); zhengp@scau.edu.cn (P.Z.); \\ binmei@scau.cn (B.S.) \\ 4 Maoming Branch, Guangdong Laboratory for Lingnan Modern Agriculture, Guangzhou 525000, China \\ * Correspondence: jmguo@scau.edu.cn (J.G.); scauok@scau.edu.cn (S.L.) \\ + These authors contributed equally to this work.
}

Citation: Mei, S.; Yu, Z.; Chen, J.; Zheng, P.; Sun, B.; Guo, J.; Liu, S. The Physiology of Postharvest Tea (Camellia sinensis) Leaves, According to Metabolic Phenotypes and Gene Expression Analysis. Molecules 2022, 27, 1708. https://doi.org/10.3390/ molecules 27051708

Academic Editor: Yukio Yoneda

Received: 6 February 2022

Accepted: 3 March 2022

Published: 5 March 2022

Publisher's Note: MDPI stays neutral with regard to jurisdictional claims in published maps and institutional affiliations.

Copyright: (C) 2022 by the authors Licensee MDPI, Basel, Switzerland. This article is an open access article distributed under the terms and conditions of the Creative Commons Attribution (CC BY) license (https:// creativecommons.org/licenses/by/ $4.0 /)$.

\begin{abstract}
Proper postharvest storage preserves horticultural products, including tea, until they can be processed. However, few studies have focused on the physiology of ripening and senescence during postharvest storage, which affects the flavor and quality of tea. In this study, physiological and biochemical indexes of the leaves of tea cultivar 'Yinghong $9^{\prime}$ preserved at a low temperature and high relative humidity $\left(15-18{ }^{\circ} \mathrm{C}\right.$ and $85-95 \%$, PTL) were compared to those of leaves stored at ambient conditions $\left(24 \pm 2{ }^{\circ} \mathrm{C}\right.$ and relative humidity of $65 \% \pm 5 \%$, UTL). Water content, chromatism, chlorophyll fluorescence, and key metabolites (caffeine, theanine, and catechins) were analyzed over a period of $24 \mathrm{~h}$, and volatilized compounds were determined after $24 \mathrm{~h}$. In addition, the expression of key biosynthesis genes for catechin, caffeine, theanine, and terpene were quantified. The results showed that water content, chromatism, and chlorophyll fluorescence of preserved leaves were more similar to fresh tea leaves than unpreserved tea leaves. After $24 \mathrm{~h}$, the content of aroma volatiles and caffeine significantly increased, while theanine decreased in both groups. Multiple catechin monomers showed distinct changes within $24 \mathrm{~h}$, and EGCG was significantly higher in preserved tea. The expression levels of CSFAS and CSTSI were consistent with the content of farnesene and theanine, respectively, but TCS1 and TCS2 expression did not correlate with caffeine content. Principal component analysis considered results from multiple indexes and suggested that the freshness of PTL was superior to that of UTL. Taken together, preservation conditions in postharvest storage caused a series of physiological and metabolic variations of tea leaves, which were different from those of unpreserved tea leaves. Comprehensive evaluation showed that the preservation conditions used in this study were effective at maintaining the freshness of tea leaves for $2-6 \mathrm{~h}$. This study illustrates the metabolic changes that occur in postharvest tea leaves, which will provide a foundation for improvements to postharvest practices for tea leaves.
\end{abstract}

Keywords: Camellia sinensis; preservation storage; postharvest metabolism; postharvest gene expression

\section{Introduction}

Tea from Camellia sinensis is among the world's three most popular beverages. Tea is rich in polyphenols, caffeine, theanine, and terpenoids, which collectively provide a wealth of benefits to humans and contribute to its unique taste and aroma [1]. Anti-aging, cancer prevention, and other health benefits continue to be uncovered, boosting tea consumption and demand [2]. With the rapid growth of the global tea industry and the increasing number of consumers, the world's per capita tea consumption has increased by an average 
of $2.8 \%$ annually in the past decade (Food and Agriculture Organization of the United Nations, https: / / www.fao.org/international-tea-day/en/, accessed on 5 December 2021).

Tea is a processed food produced from the tender leaves of Camellia sinensis. The chemical components of fresh tea leaves are essential for their market value. Nonvolatile components are generally responsible for taste, while volatile components affect aroma [3]. Similar to fruits, vegetables, and flowers, plucking tea leaves does not mean the end of life, but the beginning of post-ripening and senescence. As with other agricultural products, proper postharvest storage is critical for tea [4]. Oxidization reactions change the overall phytochemical composition of tea leaves and alter the organoleptic profile of the final tea product, decreasing its commercial value [5]. Practices adopted by enterprises typically include chilled temperature storage to preserve sensory and quality components [5].

The environment, which includes temperature and relative humidity, affects leaf metabolism during the postharvest period [6]. Many postharvest approaches have been implemented to preserve the freshness of tea leaves, with low temperature storage being the major approach to slow down metabolic activities [5]. Studies have found that tea leaves have reduced aroma content after plucking, and immediate storage at low temperature can enrich aromatic compounds $[7,8]$. However, compared to the extensive research on the compositional changes during tea processing, few studies have focused on the complex physiology of tea leaves during postharvest storage $[9,10]$. Physiological indexes and changes in tea metabolites during storage would show the influence of postharvest storage conditions on tea quality. Therefore, to improve the process of postharvest storage, it is important to understand the physiology of ripening and senescing leaves, including metabolite fluctuation and the expression of biosynthesis genes.

Although previous studies have investigated the metabolism of volatiles and other constituents, including theanine, caffeine, and catechins in postharvest tea leaves [5,8,11], few studies have integrated metabolic phenotypes and the gene expression analysis of postharvest leaves of Camellia sinensis. Enlightened by the preservation measures of other studies [8], fresh leaves were divided into two groups: preserved tea leaves (PTL) and unpreserved tea leaves (UTL). Physiological and biochemical indexes were compared among the two groups. In addition, genes associated with the biosynthesis of major metabolites were quantified. This study is a step towards clarifying the physiology of postharvest tea leaves and evaluating the effect of preservation on tea quality, which will help producers achieve greater economic benefits.

\section{Results}

\subsection{Changes in Water Content, Color, and Degree of Damage during Storage}

Suitable storage conditions play an important role in preserving freshly plucked tea leaves, and water content, color change, and degree of damage are important indexes to evaluate preservation. To explore the time-dependent changes in PTL and UTL, water content, color values $\left(\mathrm{L}^{*}, \mathrm{a}^{*}\right.$, and $\left.\mathrm{b}^{*}\right)$, and chlorophyll fluorescence $(\mathrm{Fv} / \mathrm{Fm})$ were measured at $0,1,2,4,6,12$, and $24 \mathrm{~h}$ (Figures 1 and S1).

Throughout the $24 \mathrm{~h}$ monitoring period, PTL maintained a water content level closer to that of FTL than UTL, and the difference between UTL and PTL was significantly different at $24 \mathrm{~h}(p<0.05)$. The water content of FTL was $78.49 \%$ (Figure 1$)$. After $24 \mathrm{~h}$, the water content of UTL decreased to $75.77 \%$, and PTL fluctuated between $77.15 \%$ to $78.57 \%$ water.

During storage, UTL gradually lost their luster and their color changed relative to FTL, as indicated by the color difference values ( $\mathrm{L}^{*}, \mathrm{a}^{*}$, and $\mathrm{b}^{*}$, Supplementary Figure S1). At $2 \mathrm{~h}$ postharvest, the color of UTL and PTL had not changed relative to FTL (i.e., $\Delta \mathrm{E}<2$ ); however, significant color differences were observed in UTL after $4 \mathrm{~h}(\Delta \mathrm{E}>3.5)$. On the other hand, PTL maintained an $\Delta \mathrm{E}<3$ throughout the $24 \mathrm{~h}$ monitoring period, indicating that the color difference would only be noticeable by an expert (Figure 1B). 
A

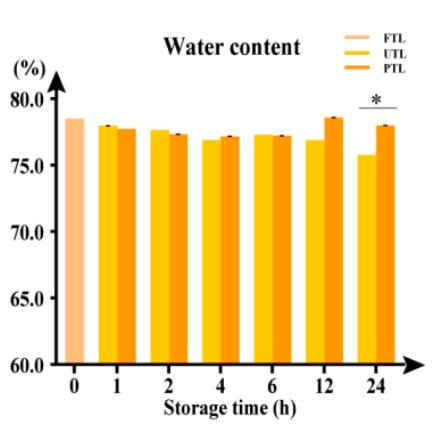

$\mathrm{B}$

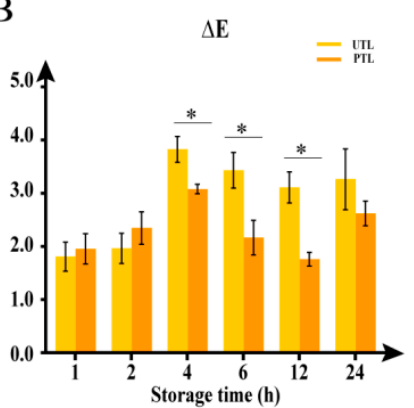

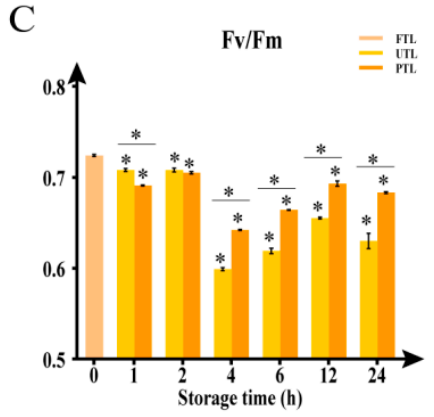

$\mathrm{D}$

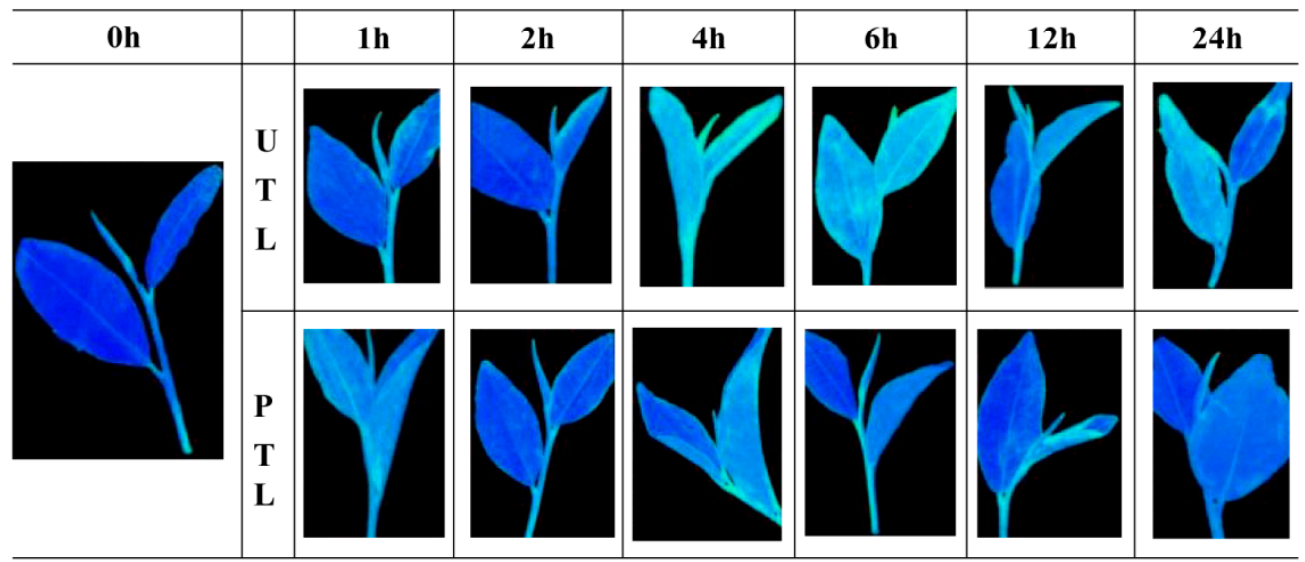

Figure 1. The effects of storage conditions on tea leaves, as indicated by changes in water content, color $(\Delta \mathrm{E})$, and leaf damage $(\mathrm{Fv} / \mathrm{Fm})$ within $24 \mathrm{~h}$. (A) The water content of FTL, UTL, and PTL at different time points. (B) $\triangle \mathrm{E}$ of UTL and PTL within $24 \mathrm{~h}$, relative to FTL. (C) The Fv /Fm values of FTL, UTL, and PTL over $24 \mathrm{~h}$. (D) Images of chlorophyll fluorescence in FTL, UTL, and PTL at different time points. Dunnett's multiple comparisons and $t$-test were used to identify significant differences $\left({ }^{*}, p<0.05\right)$. Values are the mean \pm SEM of all replicates.

Fv/Fm values (Figure 1C), calculated from chlorophyll fluorescence imaging (Figure 1D), showed that the degree of damage to UTL was much higher than the damage observed in PTL, as indicated by their lower Fv/Fm values. At $4 \mathrm{~h}$, the $\mathrm{Fv} / \mathrm{Fm}$ values significantly decreased in UTL, while the value changed only slightly in PTL. After $24 \mathrm{~h}$, the Fv / Fm value of UTL changed to 0.630 , a $13.0 \%$ decrease relative to FTL, while that of PTL dropped to 0.683 , or $5.6 \%$ less than FTL.

\subsection{Changes in Caffeine, Theanine, and Catechins Contents during Storage}

Among the numerous secondary metabolites in tea, caffeine, theanine, and catechins are highly related to tea's pleasant flavors [12]. Thus, dynamic changes to their contents were measured, via HPLC-UV/Vis spectroscopy, to evaluate the potential effects of storage conditions on tea flavor (Figure 2). Over the course of $24 \mathrm{~h}$ storage, the levels of caffeine in UTL changed greatly, while that in PTL changed relatively gradually (Figure 2A). As shown in Figure 2B, theanine content in both groups decreased markedly relative to FTL, and the contents were significantly different between the two groups $(p<0.05)$.

From the dynamic changes of catechins, we found that the contents of $C$ and EC in PTL were substantially higher than in UTL in the first $6 \mathrm{~h}$, but lower after $12 \mathrm{~h}$ (Figure 2C,D). In both groups, the contents of GC and EGC decreased after $24 \mathrm{~h}$ (Figure 2E,F), while the content of GCG significantly increased after $24 \mathrm{~h}$ (Figure 2G). ECG and EGCG were the major monomeric catechins in tea samples. By $24 \mathrm{~h}$ postharvest, ECG had reached $60 \mathrm{mg} / \mathrm{g}$ $(\mathrm{dw})$ in both PTL and UTL, while EGCG was $63.18 \mathrm{mg} / \mathrm{g}(\mathrm{dw})$ and $54.01 \mathrm{mg} / \mathrm{g}(\mathrm{dw})$, respectively, in PTL and UTL (Figure 2H,I). The content of ECG significantly increased within $24 \mathrm{~h}$ in both groups, while the content of EGCG was substantially higher in PTL 
than in UTL after $24 \mathrm{~h}$. Overall, each metabolite displayed a different trend over the course of the $24 \mathrm{~h}$ storage period that largely depended on whether they were preserved or not.

A
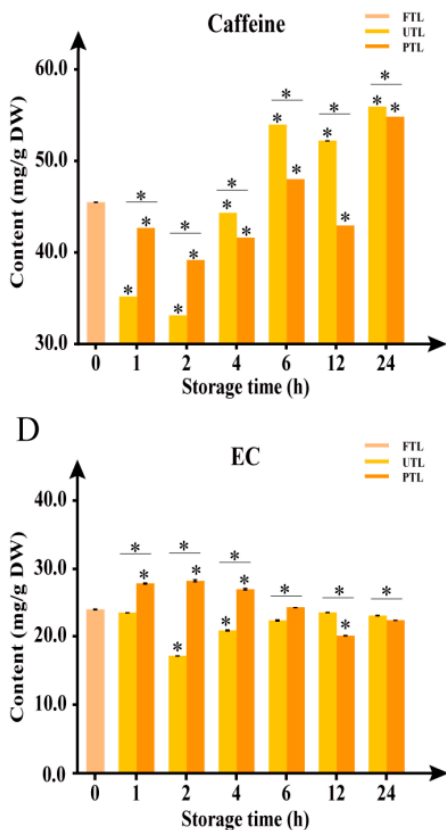

G

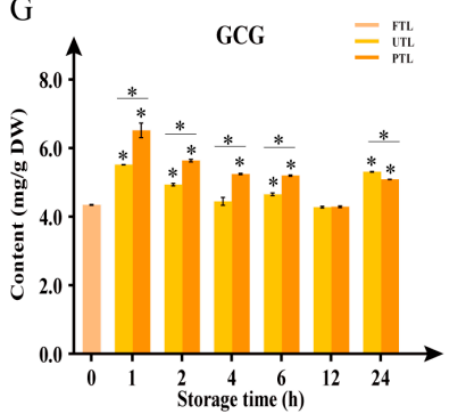

B

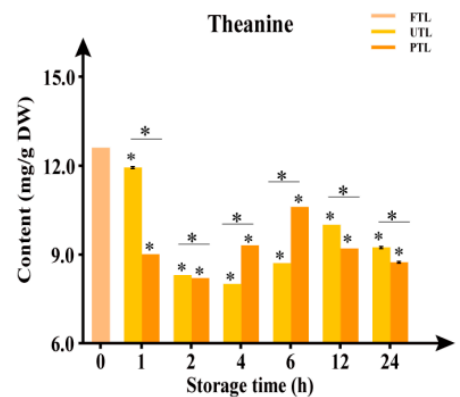

E

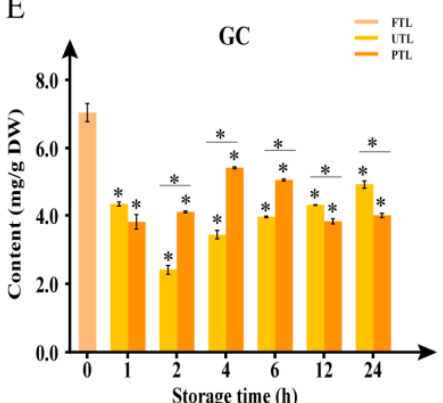

$\mathrm{H}$

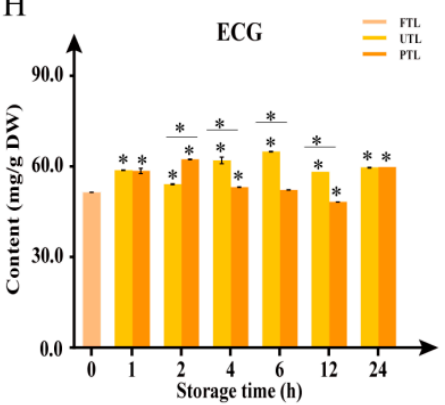

C
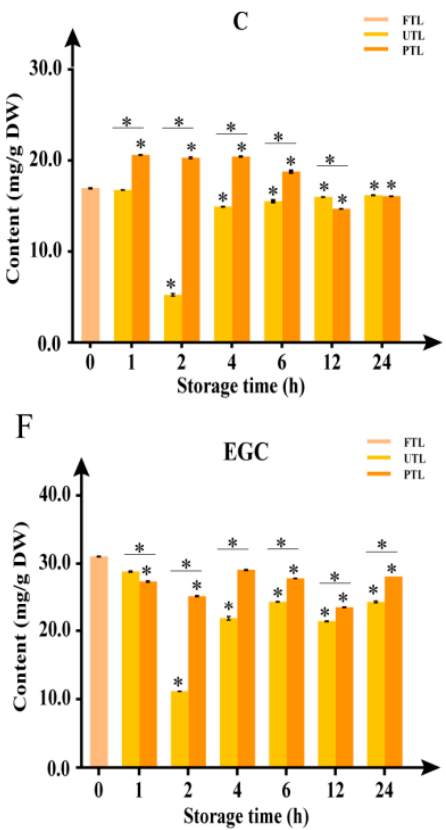

I

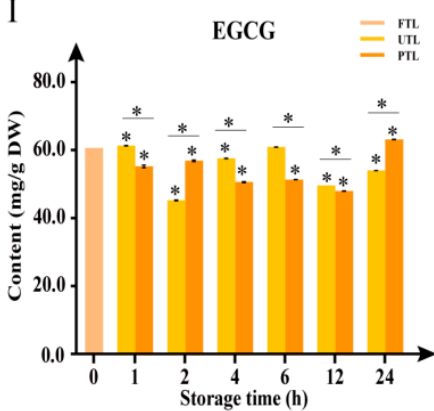

Figure 2. Changes in caffeine (A), theanine (B), and catechin (C-I) contents in preserved (PTL) and unpreserved (UTL) up to $24 \mathrm{~h}$ postharvest. C, catechin; EC, epicatechin; GC, gallocatechin; EGC, epigallocatechin; ECG, epicatechin gallate; GCG, gallocatechin gallate; EGCG, epigallocatechin gallate. Dunnett's multiple comparisons and $t$-test identified significant differences $\left({ }^{*}, p<0.05\right)$. Values are the mean \pm SEM of all replicates.

\subsection{Comprehensive Analysis of Volatilized Compounds in UTL and PTL}

HS-SPME/GC-MS analysis revealed a total of 52 volatile compounds in FTL, PTL, and UTL (Table 1) that were composed of alcohols (10), aldehydes (5), ketones (5), alkenes and terpenes (10), acids (1), alkanes (8), esters and lactones (10), and others (3). A total of 52, 37, and 34 compounds were identified in FTL, UTL, and PTL, respectively. The total content of volatilized compounds in UTL increased by $11.8 \%$, while the total in PTL increased by $28.4 \%$ (Supplementary Figure S2). As illustrated in Figure 3A, there were apparent differences in individual volatiles between the two groups. Compared with UTL, the aroma volatile content in PTL increased to a larger extent, including for 1-octen-3-ol, cis- $\beta$-farnesene, and trans- $\beta$-ionone. In addition, compounds known for their sweet, fruity, and floral odor, especially cis- $\beta$-farnesene, were more than 11.3 times higher in PTL than in UTL. 
A

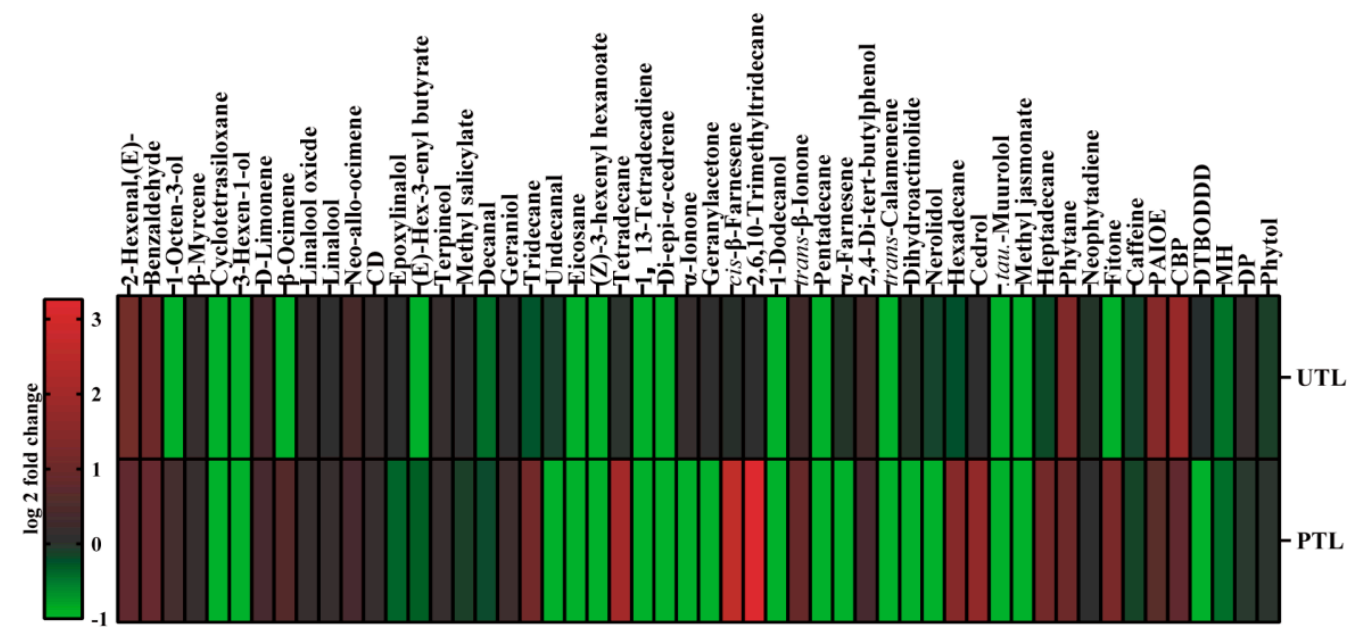

B
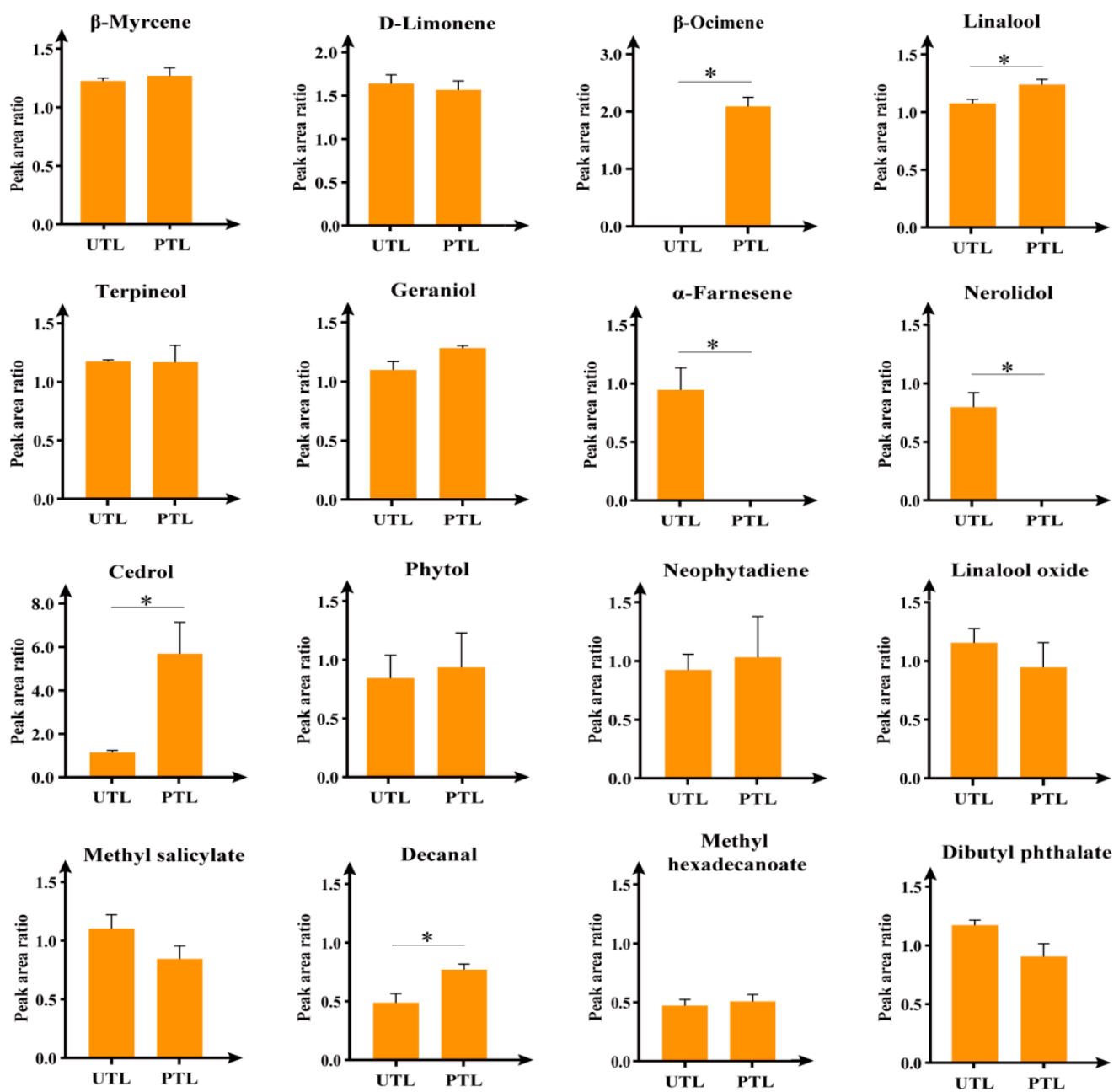

Figure 3. Changes in volatile compounds of tea leaves in UTL and PTL at $24 \mathrm{~h}$, relative to FTL. (A) Heatmap showing changes of 52 volatile compounds. Red and green represent a positive and negative fold change, respectively, relative to FTL. (B) Changes of 16 key aroma compounds in UTL and PTL. Dunnett's multiple comparisons and $t$-test were used to identify significant differences $\left({ }^{*}, p<0.05\right)$. Values are the mean \pm SEM of all replicates. CD, cyclopentasiloxane, decamethyl-; PAIOE, phthalic acid, isobutyl octyl ester; CBP, cyclohexyl butyl phthalate; DTBODDD, 7,9-Di-tertbutyl-1-oxaspiro $(4,5)$ deca-6,9-diene-2,8-dione; $\mathrm{MH}$, methyl hexadecanoate; DP, dibutyl phthalate. 
Because of the large number of volatiles, we focused on 16 major volatiles that play key roles in tea fragrance [7,13-19] (Figure 3B). There was no significant change in the contents of ten aroma volatiles, namely, $\beta$-myrcene, D-limonene, terpineol, geraniol, phytol, neophytadiene, linalool oxide, methyl salicylate, methyl hexadecanoate, and dibutyl phthalate, between PTL and UTL. In contrast, there were significant differences $(p<0.05)$ in the contents of linalool and decanal between UTL and PTL, and the differences were even greater for $\beta$-ocimene, $\alpha$-farnesene, nerolidol, and cedrol. $\alpha$-Farnesene and nerolidol were not detected in PTL, while cedrol was 5 times higher in PTL than in UTL. The results indicated that 1 -octen-3-ol, $\beta$-ocimene, cis- $\beta$-farnesene, trans- $\beta$-ionone, and cedrol increased in content under preserved storage conditions.

Table 1. Volatile compounds in PTL and UTL.

\begin{tabular}{|c|c|c|c|c|c|c|}
\hline \multirow[b]{2}{*}{ No. } & \multirow[b]{2}{*}{ Compound $^{a}$} & \multirow[b]{2}{*}{$\mathbf{R I}^{\mathbf{b}}$} & \multirow[b]{2}{*}{$\mathrm{RT}^{\mathrm{c}}$} & \multirow[b]{2}{*}{ Aroma Description ${ }^{d}$} & \multicolumn{2}{|c|}{ Relative Contents } \\
\hline & & & & & UTL & PTL \\
\hline 1 & 2-Hexenal, (E)- e & & 854 & Green, leafy, fruity & $3.312 \pm 0.507$ & $2.423 \pm 0.237$ \\
\hline 2 & Benzaldehyde ${ }^{e}$ & 967 & 962 & Almond, burnt sugar & $2.957 \pm 0.398$ & $2.706 \pm 0.764$ \\
\hline 3 & 1-Octen-3-ol ${ }^{\mathrm{e}}$ & 981 & 982 & Sweet, earthy, mushroom-like & n.d. & $1.535 \pm 0.176$ \\
\hline 4 & $\beta$-Myrcene $\mathrm{e}^{\mathrm{e}}$ & 994 & 993 & Woody, resinous, musty & $1.225 \pm 0.024$ & $1.269 \pm 0.069$ \\
\hline 5 & $\begin{array}{l}\text { Cyclotetrasiloxane, } \\
\text { octamethyl- }\end{array}$ & 1000 & & - & n.d. & n.d. \\
\hline 6 & 3-Hexen-1-ol, acetate, (Z)- e & 1009 & & Grass & n.d. & n.d. \\
\hline 7 & D-Limonene ${ }^{\mathrm{e}}$ & 1031 & 1030 & $\begin{array}{l}\text { Citrus, lemon, } \\
\text { orange-like, green }\end{array}$ & $1.639 \pm 0.103$ & $1.566 \pm 0.105$ \\
\hline 8 & $\beta$-Ocimene ${ }^{\mathrm{e}}$ & 1039 & 1044 & Sweet, herb & n.d. & $2.092 \pm 0.159$ \\
\hline 9 & Linalool oxide $\mathrm{e}^{\mathrm{e}}$ & 1083 & & Flower & $1.155 \pm 0.122$ & $1.181 \pm 0.180$ \\
\hline 10 & Linalool $^{\mathrm{e}}$ & 1104 & 1100 & $\begin{array}{l}\text { Floral, sweet, } \\
\text { grape-like, woody }\end{array}$ & $1.076 \pm 0.035$ & $1.238 \pm 0.046$ \\
\hline 11 & Neo-allo-ocimene ${ }^{\mathrm{e}}$ & 1132 & 1131 & $\begin{array}{l}\text { Sweet, floral, nutty, } \\
\text { herbal, peppery }\end{array}$ & $1.492 \pm 0.054$ & $1.606 \pm 0.089$ \\
\hline 12 & $\begin{array}{c}\text { Cyclopentasiloxane, } \\
\text { decamethyl }\end{array}$ & 1157 & & - & $1.226 \pm 0.038$ & $1.177 \pm 0.051$ \\
\hline 13 & Epoxylinalol ${ }^{\mathrm{e}}$ & 1176 & 1183 & Floral & $1.055 \pm 0.035$ & $0.548 \pm 0.028$ \\
\hline 14 & $\begin{array}{l}\text { (E)-Hex-3-enyl } \\
\text { butyrate }\end{array}$ & 1188 & 1185 & Fruity, green, vanilla, cream & n.d. & $0.612 \pm 0.095$ \\
\hline 15 & Terpineol ${ }^{\mathrm{e}}$ & 1194 & 1190 & Pleasant, floral & $1.173 \pm 0.014$ & $1.167 \pm 0.143$ \\
\hline 16 & Methyl salicylate $\mathrm{e}^{\mathrm{T}}$ & 1197 & 1191 & Minty, fresh, sweet & $1.102 \pm 0.120$ & $0.845 \pm 0.110$ \\
\hline 17 & Decanal $^{\mathrm{e}}$ & 1207 & 1200 & Soap, orange peel, tallow & $0.487 \pm 0.079$ & $0.768 \pm 0.049$ \\
\hline 18 & Geraniol $^{\mathrm{e}}$ & 1231 & 1250 & Rose-like, sweet, honey-like & $1.133 \pm 0.072$ & $1.453 \pm 0.021$ \\
\hline 19 & Tridecane $\mathrm{e}^{\mathrm{a}}$ & 1300 & & Alkane & $0.666 \pm 0.032$ & $3.259 \pm 0.312$ \\
\hline 20 & Undecanal $^{\mathrm{e}}$ & 1308 & 1308 & Rose, waxy, oily & $0.865 \pm 0.150$ & n.d. \\
\hline 21 & Eicosane $\mathrm{e}^{\mathrm{e}}$ & 1326 & & Alkane & n.d. & n.d. \\
\hline 22 & $\begin{array}{l}\text { (Z)-3-hexenyl } \\
\text { hexanoate }\end{array}$ & 1383 & & $\begin{array}{l}\text { Fruity, waxy, green, } \\
\text { fatty, winey }\end{array}$ & n.d. & n.d. \\
\hline 23 & Tetradecane $\mathrm{e}^{\mathrm{e}}$ & 1400 & & Alkane & $0.938 \pm 0.072$ & $6.995 \pm 0.752$ \\
\hline 24 & 1,13-Tetradecadiene & 1410 & & - & n.d. & n.d. \\
\hline 25 & Di-epi- $\alpha$-cedrene ${ }^{e}$ & 1419 & & - & n.d. & n.d. \\
\hline 26 & $\alpha$-Ionone $\mathrm{e}^{\mathrm{T}}$ & 1431 & 1433 & $\begin{array}{c}\text { Floral, violet-like, powdery, } \\
\text { berry-like }\end{array}$ & $1.153 \pm 0.110$ & n.d. \\
\hline 27 & Geranylacetone $^{\mathrm{e}}$ & 1455 & 1454 & Fresh floral, sweet-rosy & $1.106 \pm 0.042$ & n.d. \\
\hline 28 & cis- $\beta$-Farnesene $^{\mathrm{e}}$ & 1458 & 1457 & Citrus, green & $0.984 \pm 0.096$ & $11.089 \pm 0.956$ \\
\hline 29 & $\begin{array}{c}\text { 2,6,10- } \\
\text { Trimethyltridecane }\end{array}$ & 1462 & 1461 & - & $1.053 \pm 0.097$ & $18.202 \pm 3.610$ \\
\hline 30 & 1-Dodecanol $\mathrm{e}^{\mathrm{a}}$ & 1475 & 1480 & Sweet, fatty & n.d. & n.d. \\
\hline 31 & trans- $\beta$-Ionone $\mathrm{e}^{\mathrm{e}}$ & 1490 & 1490 & Violet-like, raspberry, floral & $1.395 \pm 0.137$ & $2.891 \pm 0.461$ \\
\hline 32 & Pentadecane ${ }^{\mathrm{e}}$ & 1500 & & Alkane & n.d. & n.d. \\
\hline 33 & $\alpha$-Farnesene $\mathrm{e}^{\mathrm{a}}$ & 1510 & 1508 & Woody, green, floral, herbal & $0.944 \pm 0.228$ & n.d. \\
\hline 34 & 2,4-Di-tert-butylphenol & 1515 & 1518 & - & $1.386 \pm 0.123$ & $1.579 \pm 0.128$ \\
\hline 35 & trans-Calamenene $\mathrm{e}^{\mathrm{e}}$ & 1529 & 1529 & Herbal, spicy & n.d. & n.d. \\
\hline
\end{tabular}


Table 1. Cont.

\begin{tabular}{|c|c|c|c|c|c|c|}
\hline \multirow[b]{2}{*}{ No. } & \multirow[b]{2}{*}{ Compound ${ }^{a}$} & \multirow[b]{2}{*}{$\mathbf{R I}^{\mathrm{b}}$} & \multirow[b]{2}{*}{$\mathrm{RT}^{\mathrm{c}}$} & \multirow[b]{2}{*}{ Aroma Description ${ }^{d}$} & \multicolumn{2}{|c|}{ Relative Contents } \\
\hline & & & & & UTL & PTL \\
\hline 36 & Dihydroactinolide $^{\mathrm{e}}$ & 1537 & 1538 & Musky, coumarin-like & $0.941 \pm 0.059$ & n.d. \\
\hline 37 & Nerolidol $^{\mathrm{e}}$ & 1567 & 1567 & Wood, flower, wax & $0.797 \pm 0.124$ & n.d. \\
\hline 38 & Hexadecane ${ }^{\mathrm{e}}$ & 1600 & & Alkane & $0.704 \pm 0.052$ & $4.483 \pm 0.112$ \\
\hline 39 & Cedrol ${ }^{\mathrm{e}}$ & 1610 & 1609 & Sweet, fruity, cedar-like & $1.147 \pm 0.090$ & $5.691 \pm 1.452$ \\
\hline 40 & tau.-Muurolol e & 1649 & 1648 & Herb, weak spice & n.d. & n.d. \\
\hline 41 & Methyl jasmonate ${ }^{\mathrm{e}}$ & 1653 & 1655.4 & Jasmine & n.d. & n.d. \\
\hline 42 & Heptadecane $\mathrm{e}^{\mathrm{e}}$ & 1700 & & Alkane & $0.764 \pm 0.072$ & $3.221 \pm 0.309$ \\
\hline 43 & Phytane & 1809 & 1795 & - & $4.193 \pm 0.358$ & $3.035 \pm 0.912$ \\
\hline 44 & Neophytadiene ${ }^{\mathrm{e}}$ & 1840 & 1837 & Fresh & $0.924 \pm 0.132$ & $1.031 \pm 0.349$ \\
\hline 45 & Fitone $\mathrm{e}^{\mathrm{e}}$ & 1847 & 1847 & - & n.d. & $3.681 \pm 1.311$ \\
\hline 46 & Caffeine & 1854 & 1842 & - & $0.801 \pm 0.087$ & $0.808 \pm 0.142$ \\
\hline 47 & $\begin{array}{l}\text { Phthalic acid, isobutyl } \\
\text { octyl ester }\end{array}$ & 1872 & & - & $4.368 \pm 0.364$ & $2.104 \pm 0.446$ \\
\hline 48 & $\begin{array}{l}\text { Cyclohexyl butyl phthalate } \\
\text { 7,9-Di-tert-butyl-1-oxaspiro }\end{array}$ & 1919 & 1892 & Mild & $5.801 \pm 0.552$ & $2.391 \pm 0.837$ \\
\hline 49 & $\begin{array}{c}(4,5) \\
\text { deca-6,9-diene-2,8-dione }\end{array}$ & 1924 & 1916.8 & - & $1.005 \pm 0.081$ & n.d. \\
\hline 50 & Methyl hexadecanoate ${ }^{\mathrm{e}}$ & 1928 & 1925 & Oily, waxy, fatty & $0.471 \pm 0.052$ & $0.508 \pm 0.058$ \\
\hline 51 & Dibutyl phthalate ${ }^{\mathrm{e}}$ & 1967 & 1969 & Slight, aromatic & $1.173 \pm 0.043$ & $0.904 \pm 0.110$ \\
\hline 52 & Phytol ${ }^{\mathrm{e}}$ & 2115 & 2116 & Floral, balsam, powdery, waxy & $0.844 \pm 0.196$ & $0.935 \pm 0.295$ \\
\hline
\end{tabular}

a Identification method: retention index in agreement with the literature value; mass spectrum comparison using the NIST 14 library. ${ }^{b}$ Retention index was calculated based on the retention time of standard saturated C9-C29 n-alkanes under the same conditions. ${ }^{c}$ The published retention index of compounds in NIST 14 library. ${ }^{\mathrm{d}}$ Aroma description found in references [14,18], the Flavornet database (https: / / www.flavornet.org/flavornet.html, accessed on 5 December 2021), and PubChem (https:/ / pubchem.ncbi.nlm.nih.gov/, accessed on 5 December 2021). e Aroma volatile compounds identified from references $[7,13,14,17-20]$, the Flavornet database (https://www. flavornet.org/flavornet.html, accessed on 5 December 2021), PubChem (https:/ / pubchem.ncbi.nlm.nih.gov / accessed on 5 December 2021), the Flavor Library (https://www.femaflavor.org/flavor-library, accessed on 5 December 2021), and Ichemistry (http:/ / www.ichemistry.cn/, accessed on 5 December 2021). '-', no aroma description information was found in the literature. 'n.d.', the compound was not detected.

\subsection{Expression Levels of Metabolite Biosynthesis Genes during Storage}

To further explore the mechanisms behind observed metabolic changes, biosynthesis genes of terpene aroma, caffeine, theanine, and catechins were analyzed by qRT-PCR at different time points in UTL and PTL (Figure 4). The terpene aroma biosynthesis gene, farnesene synthase (FAS) was significantly upregulated in PTL within $24 \mathrm{~h}$, but less so in UTL. In contrast, limonene synthase (LMS) was steadily downregulated during storage in PTL. The expression levels of germacrene D synthase (GDS) and 4-hydroxy3-methylbutenlyl diphosphate reductase (HDR) had no apparent change. Mevalonate-5pyrophosphate decarboxylase (MVD), terpene synthase 78 (TPS78), and terpene synthase 77 (TPS77) had lower expression than FTL in both groups.

The expression levels of tea caffeine synthase 1 (TCS1) and tea caffeine synthase 2 (TCS2) were upregulated at $4 \mathrm{~h}$ in PTL, but finally, they decreased at $24 \mathrm{~h}$ in both groups.

Key genes involved in theanine biosynthesis, alanine decarboxylase (AlaDC), theanine synthetase (TSI), and glutamine synthetase 2 (GS2), were analyzed. TSI was highly expressed at $12 \mathrm{~h}$ in UTL and at $6 \mathrm{~h}$ in PTL. However, AlaDC had a higher expression level in UTL than in PTL. GS2 was downregulated after $24 \mathrm{~h}$ and had a high expression level at $4 \mathrm{~h}$ in PTL.

Key catechin biosynthesis genes, flavonoid 3',5'-hydroxylase $\left(F 3^{\prime} 5^{\prime} H\right)$, flavonoid 3hydroxylase $(F 3 H)$, leucoanthocyanidin reductase $(L A R)$, anthocyanidin reductase $(A N R)$, and serine carboxypeptidase-like acyltransferase 7 (SCPL1A7) were consistently upregulated in the early hours of PTL, but the expression level decreased after $12 \mathrm{~h}$. The expression level of $F 3^{\prime} 5^{\prime} H$ and $F 3 H$ fluctuated greatly in UTL within $24 \mathrm{~h}$. LAR, ANR, and SCPL1A7 were significantly downregulated in UTL and had the lowest expression level at $24 \mathrm{~h}$. 


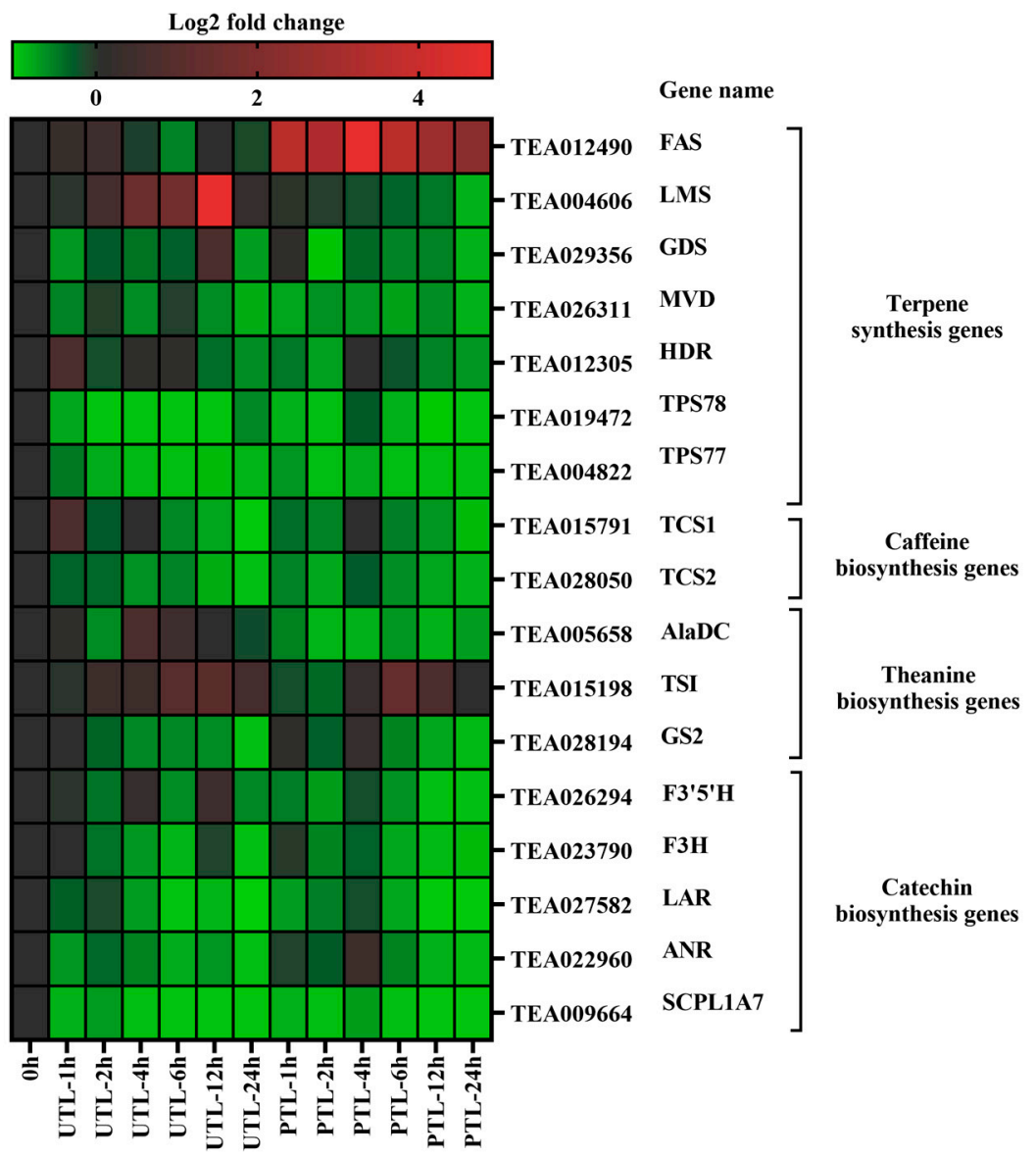

Figure 4. Heatmap for expression levels of biosynthetic genes in UTL and PTL relative to FTL. Red represents upregulation; green represents downregulation. FAS, farnesene synthase; $L M S$, limonene synthase; GDS, germacrene D synthase; $M V D$, mevalonate-5-pyrophosphate decarboxylase; HDR, 4-hydroxy-3-methylbutenlyl diphosphate reductase; TPS78, terpene synthase 78; TPS77, terpene synthase 77; TCS1, tea caffeine synthase 1 ; TCS2, tea caffeine synthase 2; AlaDC, alanine decarboxylase; TSI, theanine synthetase; GS2, glutamine synthetase 2; $F 3^{\prime} 5^{\prime} H$, flavonoid $3^{\prime}, 5^{\prime}$-hydroxylase; $F 3 H$, flavonoid 3-hydroxylase; $L A R$, leucoanthocyanidin reductase; $A N R$, anthocyanidin reductase; SCPL1A7, serine carboxypeptidase-like acyltransferase 7.

\subsection{A Comprehensive Evaluation of Quality in UTL and PTL}

PCA comprehensively evaluates sample differences based on multiple sets of index data. Physiological and biochemical property indexes for water, caffeine, theanine, and catechin content, which directly reflect the quality of tea leaves, were included in a PCA. The PC scores of the first two PCs were plotted (Figure 5): the first principal component (PC1) explained $35.3 \%$ of the total variation, and the second principal component (PC2) $21.7 \%$. The obtained PC scores indicated the difference between samples by variance: each circle represented a sample, and the distance between circles indicated the difference between and within groups. The closer the circles, the higher the similarity. When considering PTL and UTL at the same time point, PTL was closer to FTL than UTL from $2 \mathrm{~h}$ to $6 \mathrm{~h}$. The distance between PTL and FTL was much shorter than that between UTL and FTL after $2 \mathrm{~h}$, whereas the distance difference was not apparent after $12 \mathrm{~h}$, indicating that the quality of PTL was most similar to FTL in the $2 \mathrm{~h}$ to $6 \mathrm{~h}$ period. 


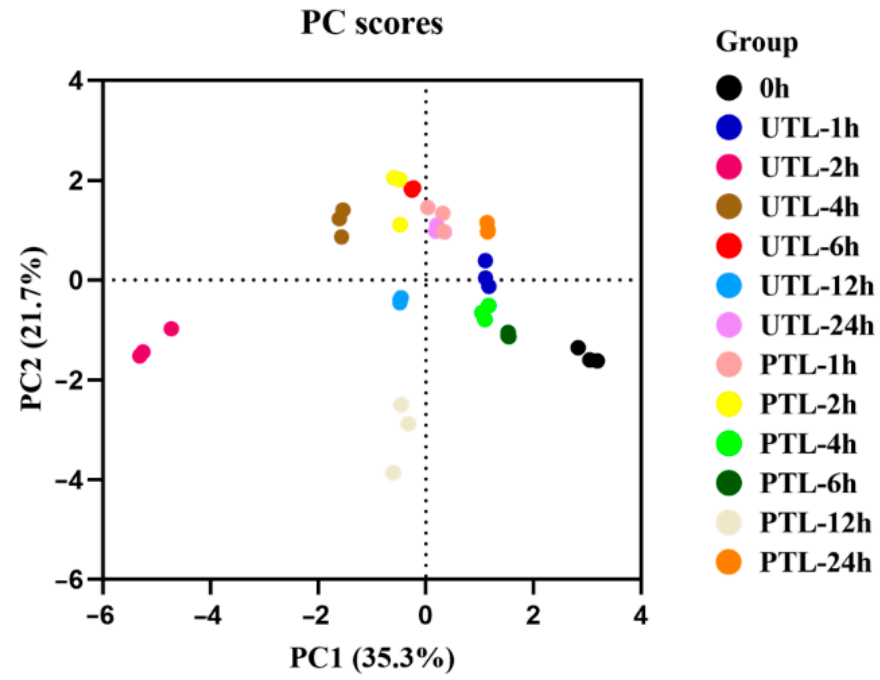

Figure 5. Graph of PC scores based on PCA.

\section{Materials and Methods}

\subsection{Plant Materials and Sampling}

The elite tea plant cultivar used in the present study, 'Yinghong 9', was planted in Yingde, Guangdong province, China $\left(24.20^{\circ} \mathrm{N}, 113.40^{\circ} \mathrm{E}\right)$. One bud and two leaves without red stain or charred edges were plucked in August 2021. Eight kilograms of fresh tea leaves were stored in a temperature and humidity control chamber (Yishi Technology Co., Ltd., Hangzhou, China) at $15-18{ }^{\circ} \mathrm{C}$ and $85-95 \%$ relative humidity (PTL), and another $8 \mathrm{~kg}$ of fresh tea leaves were placed at ambient conditions, at $24 \pm 2{ }^{\circ} \mathrm{C}$ with a relative humidity of $65 \pm 5 \%$ (UTL). Each treatment (PTL and UTL) was sampled in triplicate at 0, 1, 2, 4, 6, 12, and $24 \mathrm{~h}$ after plucking, and placed at $-80{ }^{\circ} \mathrm{C}$ until the analysis of flavor compounds and gene expression. Fresh tea leaves (FTL) served as the positive control.

\subsection{Measurement of Water Content}

The water content of FTL was detected using the suggested protocol from the Chinese National Standard GB/T8304-2013 (General Administration of Quality Supervision, Inspection, and Quarantine of the People's Republic of China, 2013) [21] with minor changes. Briefly, a clean aluminum box was dried at $103{ }^{\circ} \mathrm{C} \pm 2{ }^{\circ} \mathrm{C}$ with the cover slanted on the edge of the box for $1 \mathrm{~h}$, cooled in a desiccator to room temperature, and weighed $\left(\mathrm{m}_{1}\right.$, accurate to $0.0001 \mathrm{~g})$. Then, approximately $4 \mathrm{~g}$ of FTL $\left(\mathrm{m}_{0}\right)$ were placed in the pre-dried box and put in the desiccator at $120{ }^{\circ} \mathrm{C}$ for $2 \mathrm{~h}$ with the cover slanted on the edge of the box. After capping the box, samples were cooled in the desiccator to room temperature and weighed $\left(\mathrm{m}_{2}\right.$, accurate to $\left.0.0001 \mathrm{~g}\right)$. Finally, the sample was baked for another hour and weighed $\left(\mathrm{m}_{3}\right.$, accurate to $\left.0.0001 \mathrm{~g}\right)$ until the difference in weight between $\mathrm{m}_{2}$ and $\mathrm{m}_{3}$ did not exceed $0.0050 \mathrm{~g}$. All samples were weighed on an electronic scale (BSA224S-CW, Sartorius). The water content of the samples was calculated as: water content $(\%)=\left(m_{2}-m_{1}\right) / m_{0} \times 100 \%$.

\subsection{Measurement of Color Difference}

The color of the tea leaves was determined using a chromameter CR-400 (Konica Minolta, Tokyo, Japan). The color was measured according to the international commission on an illumination color solid scale (CIE: $\left.\mathrm{L}^{*} \mathrm{a}^{*} \mathrm{~b}^{*}\right)$ : $\mathrm{L}^{*}$ indicates lightness, $\mathrm{a}^{*}$ stands for red $(+)$, and green $(-)$, and $b^{*}$ indicates yellow $(+)$ and blue $(-)$ [22,23]. The total color difference $(\Delta \mathrm{E})$ was calculated as follows:

$$
\Delta \mathrm{E}=\sqrt{\left(\mathrm{L}_{\mathrm{ss}}-\mathrm{L}_{\mathrm{ts}}\right)^{2}+\left(\mathrm{a}_{\mathrm{ss}}-\mathrm{a}_{\mathrm{ts}}\right)^{2}+\left(\mathrm{b}_{\mathrm{ss}}-\mathrm{b}_{\mathrm{ts}}\right)^{2}}
$$


where $\mathrm{L}_{\mathrm{ss}}, \mathrm{a}_{\mathrm{ss}}$, and $\mathrm{b}_{\mathrm{ss}}$ represent the standard sample (FLT), and $\mathrm{L}_{\mathrm{ts}}, \mathrm{a}_{\mathrm{ts}}$, and $\mathrm{b}_{\mathrm{ts}}$ represent the test sample. Color difference was classified by the following scale: when $\Delta \mathrm{E}<1$, the color difference was not noticeable; when $1<\Delta \mathrm{E}<2$, the color difference was only noticeable by experienced observers; when $2<\Delta \mathrm{E}<3.5$, the color difference was noticeable by inexperienced observers; and when $3.5<\Delta \mathrm{E}<5$, the color difference was pronounced [24].

\subsection{Measurement of Chlorophyll Fluorescence (Fv/Fm)}

The maximum photochemical efficiency of PSII (Fv/Fm) was measured with an IMAGING-PAM chlorophyll fluorescence system (Heinz Walz GmbH, Effeltrich, Germany) using default parameters according to Yu's [25]. After tea leaves adapted to the dark for $20 \mathrm{~min}$, Fo was measured. Then, a one-second saturation pulse occurred that completely closed all PSII receptors, and Fm was measured. The maximum photosynthetic efficiency $(\mathrm{Fv} / \mathrm{Fm})$ was calculated as:

$$
\text { maximum photosynthetic efficiency }(\mathrm{Fv} / \mathrm{Fm})=(\mathrm{Fm}-\mathrm{Fo}) / \mathrm{Fm}
$$

\subsection{Quantification of Caffeine Contents}

Caffeine standards were purchased from Beijing Weiye Research Institute of Metrology and Technology (Beijing, China). Caffeine content was detected by HPLC-UV/Vis spectrometry according to the Chinese National Standard (GB/T 8312-2013) [26] with changes. Freeze-dried tea powder $(0.1 \mathrm{~g})$ was extracted with $30 \mathrm{~mL} \mathrm{1.5 \%} \mathrm{magnesium} \mathrm{oxide} \mathrm{in} \mathrm{ul-}$ trapure water $(w / v)$ at $100{ }^{\circ} \mathrm{C}$ for $30 \mathrm{~min}$. One $\mathrm{mL}$ of the liquid supernatant was filtered through a $0.22 \mathrm{~mm}$ Millipore membrane, and $10 \mu \mathrm{L}$ of the filtrate was injected into an XSelect HSS C18 SB column $(4.6 \times 250$ mm, 5 mm, Waters Technologies, Milford, MA, USA) at a flow rate of $0.9 \mathrm{~mL} / \mathrm{min}$, with the column at $35 \pm 1{ }^{\circ} \mathrm{C}$. Caffeine was detected at $280 \mathrm{~nm}$ on a Waters Alliance E2695 equipped with a 2489 UV/Vis detector (Waters Technologies, Milford, MA, USA). The mobile phases consisted of 100\% methanol (A) and 100\% ultrapure water (B). Compounds were eluted under isocratic conditions: 30\% A and 70\% $\mathrm{B}$.

\subsection{Quantification of Theanine Contents}

Theanine standards were purchased from Shanghai Yuanye Bio-Technology Co., Ltd. (Shanghai, China). Theanine content was detected by HPLC-UV/Vis spectroscopy according to the Chinese National Standard (GB/T 23193-2017) [27] with a Waters Alliance E2695 equipped with a 2489 UV/Vis detector (Waters Technologies, Milford, MA, USA). Fine freeze-dried tea powder $(0.1 \mathrm{~g})$ was extracted with $10 \mathrm{~mL}$ ultrapure water at $100{ }^{\circ} \mathrm{C}$ for $30 \mathrm{~min}$. One $\mathrm{mL}$ of the liquid supernatant was filtered through a $0.22 \mathrm{~mm}$ Millipore membrane, and $10 \mu \mathrm{L}$ of each filtrate was injected onto an RP-C18 column (250 mm $\times 4.0 \mathrm{~mm}$, $5 \mu \mathrm{m})$ maintained at $35 \pm 1{ }^{\circ} \mathrm{C}$. The mobile phases consisted of $100 \%$ ultrapure water $(\mathrm{A})$ and $100 \%$ acetonitrile (B). The flow rate was $0.5 \mathrm{~mL} / \mathrm{min}$, and the HPLC program was as follows: $100 \%$ solvent B from 0-12 min, 100\% B to $20 \%$ B from $12-14 \mathrm{~min}, 20 \%$ B from $14-19 \mathrm{~min}, 20 \% \mathrm{~B}$ to $100 \% \mathrm{~B}$ from $19-20 \mathrm{~min}$, and $100 \%$ B from $20-25 \mathrm{~min}$. Theanine was detected at $210 \mathrm{~nm}$.

\subsection{Quantification of Catechin Contents}

Catechin (C), epicatechin (EC), gallocatechin (GC), epigallocatechin (EGC), epicatechin gallate (ECG), gallocatechin gallate (GCG), and epigallocatechin gallate (EGCG) standards were purchased from Shanghai Yuanye Bio-Technology Co., Ltd. (Shanghai, China). C, EC, GC, EGC, ECG, GCG, and EGCG contents were detected by HPLC-UV/Vis spectroscopy based on GB/T 8313-2018 [28,29]. Briefly, $0.2 \mathrm{~g}$ fine freeze-dried tea powders were extracted with $8 \mathrm{~mL} \mathrm{70 \%} \mathrm{methanol.} \mathrm{One} \mathrm{mL}$ of the supernatant was filtered through a $0.22 \mathrm{~mm}$ Millipore membrane, and the filtrate was injected into an XSelect HSS C18 SB column $(4.6 \times 250 \mathrm{~mm}, 5 \mathrm{~mm}$, Waters Technologies, Milford, MA, USA). Catechin monomers were eluted with $0.1 \%$ aqueous formic acid (A) and 100\% acetonitrile (B) as the mobile phases, using a gradient elution program. For the first five minutes, the mobile phase was $8 \%$; 
then from $5 \mathrm{~min}$ to $14 \mathrm{~min}$, B was increased from 8-25\%; finally, B was decreased from 25-8\% from 14-30 min. Catechins were detected at $280 \mathrm{~nm}$.

\subsection{Analysis of Microextraction Compounds}

Head-space solid-phase micro extraction/gas chromatography-mass spectrometry (HS-SPME/GC-MS) was used to analyze volatile compounds [17]. Briefly, $0.2 \mathrm{~g}$ FTL powders spiked with $10 \mu \mathrm{L}$ internal standard solution $(8.64 \mu \mathrm{g} / \mathrm{mL}$ ethyl decanoate in dichloromethane) was added to a $2 \mathrm{~mL} \mathrm{NaCl}$ saturated solution in a $15 \mathrm{~mL}$ headspace vial (Agilent, MA, USA). The head-space vials were sealed with seal caps, and tin foil paper tied with adhesive tape was placed over the sealed cap. A divinylbenzene/carboxen/polydimethylsiloxane (DVB/CAR/PDMS) fiber (50/30 $\mu \mathrm{m}$ inner diameter, $2 \mathrm{~cm}$ length) (Supelco, Darmstadt, Germany) was inserted into the head-space vial containing the sample for $40 \mathrm{~min}$ at $80{ }^{\circ} \mathrm{C}$. After microextraction, the fiber was kept in the GC port for desorption for $3 \mathrm{~min}$. An Agilent GC-MS 1890B-5977A (Agilent, Santa Clara, CA, USA) was employed for volatiles analysis. The HP-5MS chromatographic column $(30 \mathrm{~m} \times 0.25 \mathrm{~mm} \times 0.25 \mu \mathrm{m})$ was loaded with high purity helium at a flow rate of $1.0 \mathrm{~mL} / \mathrm{min}$. The inlet and interface temperatures were $250{ }^{\circ} \mathrm{C}$; the oven temperature was maintained at $50{ }^{\circ} \mathrm{C}$ for $1 \mathrm{~min}$ and then increased to $220^{\circ} \mathrm{C}$ at a rate of $5{ }^{\circ} \mathrm{C} / \mathrm{min}$ for $5 \mathrm{~min}$. Ion source electron energy and temperature were $70 \mathrm{ev}$ and $230{ }^{\circ} \mathrm{C}$, respectively. Mass spectra were acquired in splitless mode within the mass range of 30-400 amu. Volatile compounds were identified based on their retention indices (RI) and similarity to spectra within the NIST 14 database. The retention times of standard saturated C9-C29 n-alkanes were analyzed under the same conditions to calculate RI. Volatile compounds with mass spectral match factors over 75 and differences between RI and RIs less than 30 were deemed acceptable.

\subsection{Analysis of Gene Expression}

Total RNA was extracted using a HiPure Plant RNA Mini Kit B (Magen, Guangzhou, China) according to the manufacturer's instructions. cDNA synthesis was performed by reverse transcription of screened RNA in accordance with the protocol for the HiScript ${ }^{\circledR}$ III RT SuperMix for qPCR (+gDNA wiper) (Vazyme, Nanjing, China). qRT-PCR was performed with a BioRad CFX384 ${ }^{\mathrm{TM}}$ Real-Time System (Bio-Rad, Hercules, CA, USA) under the following operating conditions: $95^{\circ} \mathrm{C}$ for $5 \mathrm{~min}, 40$ cycles of $95^{\circ} \mathrm{C}$ for $10 \mathrm{~s}$, $55^{\circ} \mathrm{C}$ for $10 \mathrm{~s}$, and $72^{\circ} \mathrm{C}$ for $30 \mathrm{~s}$. Actin was used as the internal reference, and the relative expression levels were calculated using the $2^{-\triangle \triangle C T}$ method [30]. Primers used in this study are listed in Supplementary Table S1.

\subsection{Statistical Analysis}

Excel 2019 (Microsoft, Washington, DC, USA) was used to process the data. Heat maps and principal component analysis (PCA) were generated with GraphPad Prism 9.0 (GraphPad Software, San Diego, CA, USA). Dunnett's multiple comparisons and $t$-test, also calculated by GraphPad Prism 9.0, were used to analyze the statistics, and differences were considered statistically significant when $p<0.05\left(^{*}\right)$.

\section{Discussion}

In green tea production, which does not include fermentation, the optimal choice is to process fresh tea leaves immediately postharvest [31]. However, many fresh tea leaves are picked simultaneously in spring, and it is not feasible to process them in time before quality begins to deteriorate [32]. This poses a problem for producers: how to store postharvest fresh leaves to maintain leaf quality? Therefore, it is necessary to determine best practices for storing fresh leaves postharvest to ameliorate the effects of processing delay on tea quality [5]. Low temperature and high relative humidity are key factors that affect the quality of horticultural products. In this study, postharvest tea leaves were stored for $24 \mathrm{~h}$ 
under preserved or unpreserved conditions to compare the preservation effect, which was assessed with physiological and biochemical indexes.

Fresh tea leaves adjust their physiological conditions to adapt to different storage environments by absorbing and releasing water; thus, water content is one of the essential factors affecting the postharvest preservation of tea leaves. In this study, we found that PTL maintained a high level of water, which was close to the initial stage. The water contents of UTL decreased more than PTL after $24 \mathrm{~h}(75.77 \%$ vs. $77.15 \%$, respectively), and the difference between the two groups was significant $(p<0.05)$. A previous study showed that, after $6 \mathrm{~h}$, the water content of tea leaves decreased to 63.8-68.1\% [17]. The relatively high water content in UTL from this study might have been caused by the storage method: we kept fresh leaves in a basket without spreading, which probably slowed down water loss. Furthermore, the atmospheric humidity during storage of the UTL was somewhat high $(60 \% \sim 70 \%)$, which may have inhibited the transpiration rate of the tea leaves during the $24 \mathrm{~h}$ storage period $[33,34]$. Even though the water content showed little overall change in the two groups, low temperature $\left(15-18^{\circ} \mathrm{C}\right)$ and high humidity $(85-95 \%)$ for PTL had a substantially better preservation effect, as indicated by $\Delta \mathrm{E}$ and $\mathrm{Fv} / \mathrm{Fm}$ (Figure 1B,C).

Caffeine, theanine, catechins, and aroma volatiles are essential for tea quality and market value; their contents determine the color, freshness, strength, and aroma of tea [35]. Caffeine, responsible for the refreshed feelings tea can bring, is the main tea alkaloid accounting for $2-4 \%$ of tea dry weight [20]. Theanine contributes sweet and savory tastes, while catechins are responsible for the color, bitterness, and astringency of tea [2]. In a previous study, harvested tea leaves underwent a processing delay of $6,12,18$, or $24 \mathrm{~h}$ at temperatures of 0,5 , and $25^{\circ} \mathrm{C}$ to investigate the effect of postharvest processing and storage of Japanese-style green tea [5]. Analyzed green tea constituents included theanine, caffeine, and catechins. These metabolites displayed a substantial decrease when tea was stored at $25{ }^{\circ} \mathrm{C}$ postharvest. However, in this study, it seemed the decreased level of these metabolites was less than that measured in previous studies. The disparity may be attributed to the specific tea cultivar, or to conditions other than temperature that differed (e.g., the relative humidity). Aromatic components, such as 1-octen-3-OL, $\beta$-ocimene, cis$\beta$-farnesene, and cedrol, significantly increased in PTL, consistent with previous studies employing low temperature conditions $[8,36]$. The patterns of changes to caffeine, theanine, and catechin content were distinctly different between PTL and UTL over the $24 \mathrm{~h}$ period.

To further understand the molecular mechanisms behind these metabolic differences, qRT-PCR was used to detect changes in the expression of CBGs, FBGs, TBGs, and TPSGs during storage. Interestingly, the expression levels of some genes were consistent with the measured contents of metabolites, such as $F A S$, which was correlative to the $\beta$-farnesene content, and TSI, which had the strongest correlation to theanine content. However, the expression levels of TCS1 and TCS2 were inconsistent with the caffeine content. We speculate that the high caffeine content was due to the transformation of other tea alkaloids into caffeine instead of de novo biosynthesis during preservation, but this needs to be further addressed.

The physiological and biochemical indexes of tea cultivar 'Yinghong $9^{\prime}$ were used to evaluate the ability of preservation under low temperatures and high humidity to maintain the quality of tea leaves postharvest. Through a comprehensive assessment by PCA, we found that the preservation effect of PTL took effect from $2 \mathrm{~h}$ to $6 \mathrm{~h}$. However, future studies using prolonged storage time and measuring a larger number of substances and genes are necessary to further explore the induction mechanism of low-temperature preservation.

\section{Conclusions}

In summary, our study combined metabolic phenotypes and gene expression to analyze physiological changes and evaluate the effects of postharvest tea leaf preservation. The inhibition of water evaporation in PTL did not lead to a sudden drop in water content, and $\Delta \mathrm{E}$ and $\mathrm{Fv} / \mathrm{Fm}$ data during the period of storage showed that the PTL had a lower degree of damage than UTL. The contents of secondary metabolites varied significantly 
according to storage mode and time. Volatile aroma components 1-octen-3-ol, $\beta$-ocimene, cis- $\beta$-farnesene, and trans- $\beta$-ionone were the main increased components in PTL, and it was shown through comprehensive judgment that PTL maintained a preferable cedrol. Moreover, the biosynthetic genes were linked to the synthesis of metabolites and terpenes, so at the molecular level, we found that CSFAS in TPSGs and CsTSI in TBGs showed the same trend as farnesene and theanine, indicating that the synthesis of farnesene and theanine were regulated by the above genes, respectively. Prime freshness was found during the period of $2 \mathrm{~h}$ to $6 \mathrm{~h}$, which provides a storage time scheme for preserving fresh tea leaves in short time for production.

Supplementary Materials: The following supporting information can be downloaded online. Table S1: PCR primers used for gene expression analysis; Figure S1: Changes in the values of L* (A), $\mathrm{a}^{*}(\mathrm{~B})$, and $\mathrm{b}^{*}(\mathrm{C})$ in UTL and PTL at different time points and FTL at $0 \mathrm{~h}$. Figure S2: Total volatile compounds (A) and aroma compounds (B) contents in FTL, UTL, and PTL at 24 h postharvest.

Author Contributions: J.C. performed qRT-PCR and analyzed and interpreted the data; Z.Y. made the data charts and wrote the manuscript; S.L. conceived the project and supervised the research. S.M. carried out the HPLC analyses; S.M., J.C., J.G. and B.S. collected the materials for the experiments and provided useful suggestions; P.Z. and S.L. reviewed and edited the manuscript; J.G. funded the research and reviewed the manuscript; S.L., J.G. and S.M. designed the project, supervised the research, interpreted the data, and edited the manuscript. All authors have read and agreed to the published version of the manuscript.

Funding: This work was supported by the Independent Research and Development Projects of Maoming Laboratory (Jiaming Guo, 2021ZZ003), and Enhance the Tea Technological Capability of Cities and Counties to Promote Industrial Development Projects (Jiaming Guo, 890-2020-XMZC-259301-0001).

Institutional Review Board Statement: Not applicable.

Informed Consent Statement: Not applicable.

Data Availability Statement: Not applicable.

Conflicts of Interest: The authors declare no conflict of interest.

Sample Availability: Samples of the compounds are not available from the authors.

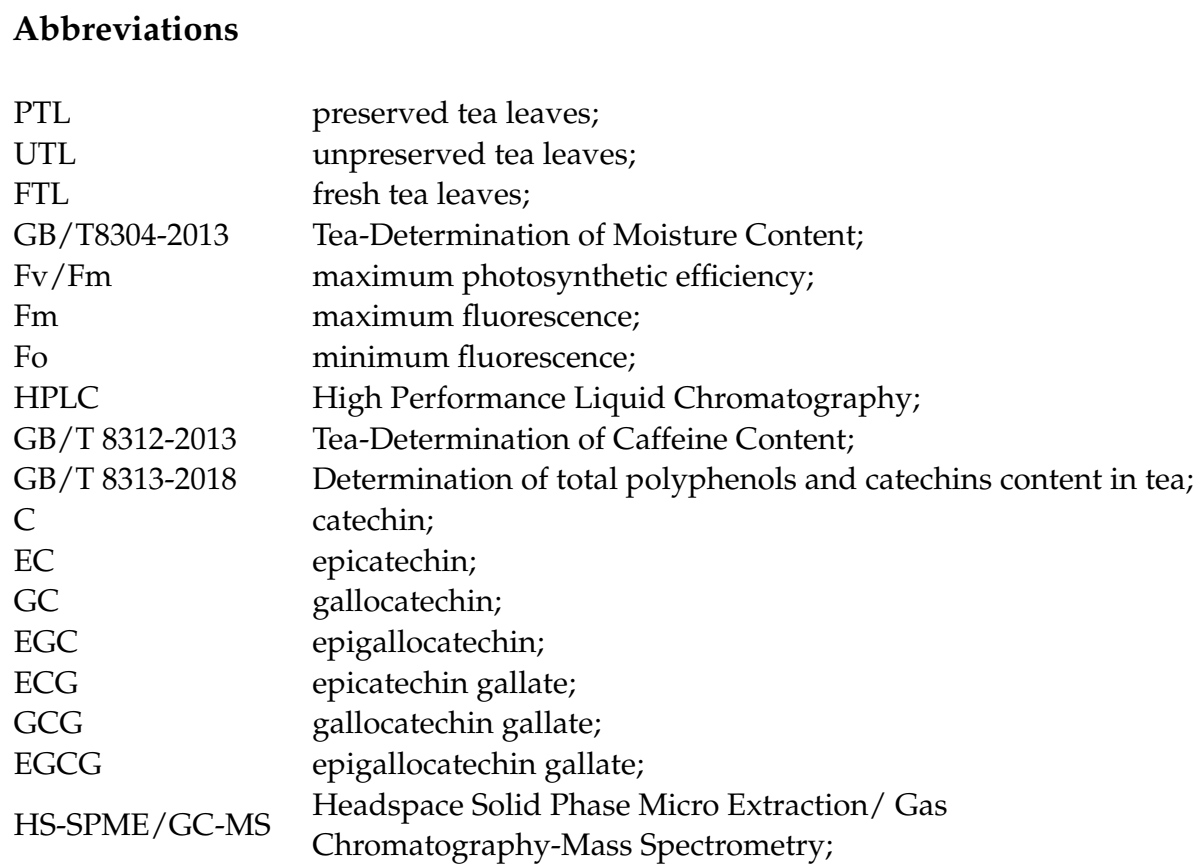




$\begin{array}{ll}\text { DVB/CAR/PDMS } & \text { divinylbenzene/carboxen/polydimethylsiloxane; } \\ \text { RI } & \text { retention indices; } \\ \text { RIs } & \text { retention indices with the values provided by the NIST 14 database; } \\ \text { MS } & \text { mass spectrum comparison using NIST 14 library; } \\ \text { qRT-PCR } & \text { quantitative real-time PCR; } \\ \text { PCA } & \text { principal component analysis; } \\ \text { CD } & \text { Cyclopentasiloxane, decamethyl-; } \\ \text { PAIOE } & \text { Phthalic acid, isobutyl octyl ester; } \\ \text { CBP } & \text { Cyclohexyl butyl phthalate; } \\ \text { DTBODDD } & \text { 7,9-Di-tert-butyl-1-oxaspiro (4,5) deca-6,9-diene-2,8-dione; } \\ \text { MH } & \text { Methyl hexadecanoate; } \\ \text { DP } & \text { Dibutyl phthalate; } \\ \text { CBGs } & \text { catechin biosynthesis genes; } \\ \text { FBGs } & \text { caffeine biosynthesis genes; } \\ \text { TBGs } & \text { theanine biosynthesis genes; } \\ \text { TPSGs } & \text { terpene synthesis genes; } \\ \text { FAS } & \text { farnesene synthase; } \\ \text { LMS } & \text { limonene synthase; } \\ \text { GDS } & \text { germacrene D synthase; } \\ \text { MVD } & \text { mevalonate-5-pyrophosphate decarboxylase; } \\ \text { HDR } & \text { 4-hydroxy-3-methylbutenlyl diphosphate reductase; } \\ \text { TPS78 } & \text { terpene synthase 78; } \\ \text { TPS77 } & \text { terpene synthase 77; } \\ \text { TCS1 } & \text { tea caffeine synthase 1; } \\ \text { TCS2 } & \text { tea caffeine synthase 2; } \\ \text { AlaDC } & \text { alanine decarboxylase; } \\ \text { TSI } & \text { theanine synthetase; } \\ \text { GS2 } & \text { glutamine synthetase 2; } \\ \text { F3'5'H } & \text { flavonoid 3', } 5^{\prime} \text {-hydroxylase; } \\ \text { F3H } & \text { flavonoid 3-hydroxylase; } \\ \text { LAR } & \text { leucoanthocyanidin reductase; } \\ \text { ANR } & \text { anthocyanidin reductase; } \\ \text { SCPL1A7 } & \text { serine carboxypeptidase-like acyltransferases 7; } \\ \text { PC1 } & \text { the first Principal Component; } \\ \text { PC2 } & \end{array}$

\section{References}

1. Yu, X.; Li, Y.; He, C.; Zhou, J.; Chen, Y.; Yu, Z.; Wang, P.; Ni, D. Nonvolatile Metabolism in Postharvest Tea (Camellia sinensis L.) Leaves: Effects of Different Withering Treatments on Nonvolatile Metabolites, Gene Expression Levels, and Enzyme Activity. Food Chem. 2020, 327, 126992. [CrossRef]

2. Gong, A.-D.; Lian, S.-B.; Wu, N.-N.; Zhou, Y.-J.; Zhao, S.-Q.; Zhang, L.-M.; Cheng, L.; Yuan, H.-Y. Integrated Transcriptomics and Metabolomics Analysis of Catechins, Caffeine and Theanine Biosynthesis in Tea Plant (Camellia sinensis) over the Course of Seasons. BMC Plant Biol. 2020, 20, 294. [CrossRef]

3. Rawat, R.; Gulati, A.; Kiran Babu, G.D.; Acharya, R.; Kaul, V.K.; Singh, B. Characterization of Volatile Components of Kangra Orthodox Black Tea by Gas Chromatography-Mass Spectrometry. Food Chem. 2007, 105, 229-235. [CrossRef]

4. Brasil, I.M.; Siddiqui, M.W. Chapter 1-Postharvest quality of fruits and vegetables: An overview. In Preharvest Modulation of Postharvest Fruit and Vegetable Quality; Siddiqui, M.W., Ed.; Academic Press: Basel, Switzerland, 2018; pp. 1-40. ISBN 978-0-12809807-3.

5. Krahe, J.; Krahe, M.A.; Naumovski, N. The Implications of Post-Harvest Storage Time and Temperature on the Phytochemical Composition and Quality of Japanese-Styled Green Tea Grown in Australia: A Food Loss and Waste Recovery Opportunity. Beverages 2021, 7, 25. [CrossRef]

6. Guo, J.; Chen, J.; Zhang, M.; Lv, E. Research Status and Prospect of Storage and Transportation Technology of Fresh Tea Leaves. China Tea 2020, 42, 11-15.

7. Katsuno, T.; Kasuga, H.; Kusano, Y.; Yaguchi, Y.; Tomomura, M.; Cui, J.; Yang, Z.; Baldermann, S.; Nakamura, Y.; Ohnishi, T.; et al. Characterisation of Odorant Compounds and Their Biochemical Formation in Green Tea with a Low Temperature Storage Process. Food Chem. 2014, 148, 388-395. [CrossRef]

8. Yu, X.; He, C.; Li, Y.; Zhou, J.; Chen, Y.; Yu, Z.; Wang, Y.; Ni, D.; Yu, X.; He, C.; et al. Effects of Different Spreading Treatments on the Formation of Aroma Quality in Green Tea. Beverage Plant Res. 2021, 1, 1-11. [CrossRef] 
9. Cui, J.; Zhai, X.; Guo, D.; Du, W.; Gao, T.; Zhou, J.; Schwab, W.G.; Song, C. Characterization of Key Odorants in Xinyang Maojian Green Tea and Their Changes During the Manufacturing Process. J. Agric. Food Chem. 2022, 70, 279-288. [CrossRef]

10. Liu, Z.; Chen, F.; Sun, J.; Ni, L. Dynamic Changes of Volatile and Phenolic Components during the Whole Manufacturing Process of Wuyi Rock Tea (Rougui). Food Chem. 2022, 367, 130624. [CrossRef]

11. Hu, D.; Chen, W.; Ma, C.; Lv, E.; Miao, A.; Qiao, X. Changes in Contents of Quality Related Components of Tea Leaves under Different Preservation. Modern Food Sci. Technol. 2021, 95, 110-115. [CrossRef]

12. Wei, C.; Yang, H.; Wang, S.; Zhao, J.; Liu, C.; Gao, L.; Xia, E.; Lu, Y.; Tai, Y.; She, G.; et al. Draft Genome Sequence of Camellia Sinensis Var. Sinensis Provides Insights into the Evolution of the Tea Genome and Tea Quality. Proc. Natl. Acad. Sci. USA 2018, 115, E4151-E4158. [CrossRef]

13. Feng, Z.; Li, Y.; Li, M.; Wang, Y.; Zhang, L.; Wan, X.; Yang, X. Tea Aroma Formation from Six Model Manufacturing Processes. Food Chem. 2019, 285, 347-354. [CrossRef] [PubMed]

14. Guo, X.; Ho, C.-T.; Schwab, W.; Wan, X. Effect of the Roasting Degree on Flavor Quality of Large-Leaf Yellow Tea. Food Chem. 2021, 347, 129016. [CrossRef]

15. Ho, C.-T.; Zheng, X.; Li, S. Tea Aroma Formation. Food Sci. Hum. Wellness 2015, 4, 9-27. [CrossRef]

16. Ma, C.; Li, J.; Chen, W.; Wang, W.; Qi, D.; Pang, S.; Miao, A. Study of the Aroma Formation and Transformation during the Manufacturing Process of Oolong Tea by Solid-Phase Micro-Extraction and Gas Chromatography-Mass Spectrometry Combined with Chemometrics. Food Res. Int. 2018, 108, 413-422. [CrossRef] [PubMed]

17. Qiao, D.; Mi, X.; An, Y.; Xie, H.; Cao, K.; Chen, H.; Chen, M.; Liu, S.; Chen, J.; Wei, C. Integrated Metabolic Phenotypes and Gene Expression Profiles Revealed the Effect of Spreading on Aroma Volatiles Formation in Postharvest Leaves of Green Tea. Food Res. Int. 2021, 149, 110680. [CrossRef] [PubMed]

18. Xiao, Z.; Wang, H.; Niu, Y.; Liu, Q.; Zhu, J.; Chen, H.; Ma, N. Characterization of Aroma Compositions in Different Chinese Congou Black Teas Using GC-MS and GC-O Combined with Partial Least Squares Regression. Flavour Fragr. J. 2017, 32, 265-276. [CrossRef]

19. Yang, Y.; Hua, J.; Deng, Y.; Jiang, Y.; Qian, M.C.; Wang, J.; Li, J.; Zhang, M.; Dong, C.; Yuan, H. Aroma Dynamic Characteristics during the Process of Variable-Temperature Final Firing of Congou Black Tea by Electronic Nose and Comprehensive TwoDimensional Gas Chromatography Coupled to Time-of-Flight Mass Spectrometry. Food Res. Int. 2020, 137, 109656. [CrossRef]

20. Ma, W.; Kang, X.; Liu, P.; She, K.; Zhang, Y.; Lin, X.; Li, B.; Chen, Z. The NAC-like Transcription Factor CsNAC7 Positively Regulates the Caffeine Biosynthesis-Related Gene YhNMT1 in Camellia sinensis. Hortic. Res. 2022, 9, uhab046. [CrossRef]

21. Hangzhou Tea Research Institute, China Coop; National Center for Tea Quality Inspection and Testing; Xiamen Empereur Tea Co., LTD. Tea-Determination of Moisture Content; China Standards Press: Beijing, China, 2013.

22. Shen, T.; Han, M.; Liu, Q.; Yang, C.; Meng, J.; Li, H. Pigment Profile and Gene Analysis Revealed the Reasons of Petal Color Difference of Crabapples. Braz. J. Bot. 2021, 44, 287-296. [CrossRef]

23. Huang, D.; Qiu, Q.; Wang, Y.; Wang, Y.; Lu, Y.; Fan, D.; Wang, X. Rapid Identification of Different Grades of Huangshan Maofeng Tea Using Ultraviolet Spectrum and Color Difference. Molecules 2020, 25, 4665. [CrossRef] [PubMed]

24. Biró, B.; Fodor, R.; Szedljak, I.; Pásztor-Huszár, K.; Gere, A. Buckwheat-Pasta Enriched with Silkworm Powder: Technological Analysis and Sensory Evaluation. LWT 2019, 116, 108542. [CrossRef]

25. Yu, B.; Ming, F.; Liang, Y.; Wang, Y.; Gan, Y.; Qiu, Z.; Yan, S.; Cao, B. Heat Stress Resistance Mechanisms of Two Cucumber Varieties from Different Regions. Int. J. Mol. Sci. 2022, 23, 1817. [CrossRef] [PubMed]

26. Hangzhou Tea Research Institute, China Coop; National Center for Tea Quality Inspection and Testing. Tea-Determination of Caffeine Content; China Standards Press: Beijing, China, 2013.

27. Hangzhou Tea Research Institute, China Coop; National Center for Tea Quality Inspection and Testing; National Food Quality Supervision and Inspection Center; Quanzhou Entry-Exit Inspection and Quarantine Bureau and Comprehensive Technical Service Center; Fujian Richun Industrial Co., LTD. Determination of Theanine in Tea-Using High Performance Liquid Chromatography; China Standards Press: Beijing, China, 2017.

28. Li, J.; Liu, S.; Chen, P.; Cai, J.; Tang, S.; Yang, W.; Cao, F.; Zheng, P.; Sun, B. Systematic Analysis of the R2R3-MYB Family in Camellia sinensis: Evidence for Galloylated Catechins Biosynthesis Regulation. Front. Plant Sci. 2022, 12, 782220. [CrossRef]

29. Hangzhou Tea Research Institute, China Coop; National Center for Tea Quality Inspection and Testing; Quanzhou Entry-Exit Inspection and Quarantine Bureau and Comprehensive Technical Service Center; Fujian Richun Industrial Co., LTD. Determination of Total Polyphenols and Catechins Content in Tea; China Standards Press: Beijing, China, 2018.

30. Livak, K.J.; Schmittgen, T.D. Analysis of Relative Gene Expression Data Using Real-Time Quantitative PCR and the 2- $\Delta \Delta C \mathrm{~T}$ Method. Methods 2001, 25, 402-408. [CrossRef]

31. Ning, J.; Li, D.; Luo, X.; Ding, D.; Song, Y.; Zhang, Z.; Wan, X. Stepwise Identification of Six Tea (Camellia sinensis (L.)) Categories Based on Catechins, Caffeine, and Theanine Contents Combined with Fisher Discriminant Analysis. Food Anal. Methods 2016, 9 , 3242-3250. [CrossRef]

32. Han, Z.-X.; Rana, M.M.; Liu, G.-F.; Gao, M.-J.; Li, D.-X.; Wu, F.-G.; Li, X.-B.; Wan, X.-C.; Wei, S. Green Tea Flavour Determinants and Their Changes over Manufacturing Processes. Food Chem. 2016, 212, 739-748. [CrossRef]

33. Rawson, H.M.; Begg, J.E.; Woodward, R.G. The Effect of Atmospheric Humidity on Photosynthesis, Transpiration and Water Use Efficiency of Leaves of Several Plant Species. Planta 1977, 134, 5-10. [CrossRef]

34. GRANTZ, D.A. Plant Response to Atmospheric Humidity. Plant Cell Environ. 1990, 13, 667-679. [CrossRef] 
35. Xia, E.-H.; Zhang, H.-B.; Sheng, J.; Li, K.; Zhang, Q.-J.; Kim, C.; Zhang, Y.; Liu, Y.; Zhu, T.; Li, W.; et al. The Tea Tree Genome Provides Insights into Tea Flavor and Independent Evolution of Caffeine Biosynthesis. Mol. Plant 2017, 10, 866-877. [CrossRef]

36. Shao, C.; Zhang, C.; Lv, Z.; Shen, C. Pre- and Post-Harvest Exposure to Stress Influence Quality-Related Metabolites in Fresh Tea Leaves (Camellia sinensis). Sci. Hortic. 2021, 281, 109984. [CrossRef] 